\title{
Cancer Survivorship: A Growing Role for Physiatric Care
}

\author{
Sean Robinson Smith, MD, Andrew G. Reish, DO, Cody Andrews, MD
}

\section{Introduction}

Cancer survivors are growing in number, with an estimated 14.5 million people alive in the United States with a diagnosis of cancer and an expected 19 million by 2024 [1]. Many cancer survivors have well-documented medical needs related to the cancer diagnosis and treatment [2]. Survivorship represents a distinct period along the continuum of cancer care and necessitates a unique approach to meet the demands of this patient population. As a result, the Commission on Cancer, a program of the American College of Surgeons which accredits hospital cancer centers based on established quality standards, is requiring that by 2015 all designated cancer centers have a survivorship care plan in place for patients upon the completion of acute treatment for malignancy [3]. This treatment typically consists of a combination of chemotherapy, radiation therapy, and surgery. The Commission on Cancer mandate is informed by the 2005 Institute of Medicine report, "From Cancer Patient to Cancer Survivor: Lost in Transition" [4] and aims to create a structure to (1) screen for recurrent and new cancers; (2) try to prevent recurrence of cancer; (3) identify and manage late effects of the cancer or its treatment; and (4) improve coordination between oncology providers, primary care physicians, and specialists. Different models for survivorship exist, including those that begin at diagnosis and after primary treatment [5], but any interpretation of survivorship must reasonably conclude that significant morbidity and health risks are directly or indirectly associated with the cancer diagnosis even after treatment is presumably complete and that patients will require ongoing medical care to treat these impairments even if they have no evidence of recurrent disease.

Many symptoms and conditions intrinsic to cancer and/or its treatment lead to physical and cognitive impairment, which may require expert evaluation by a multidisciplinary team led by a physiatrist [2]. In fact, physical impairments have been described as the most bothersome comorbidity in patients with a cancer diagnosis $[2,6]$. Cancer diagnoses with many long-term survivors include breast, prostate, head and neck, hematologic, and sarcoma. Common symptoms experienced by survivors of these diagnoses are wide ranging and include musculoskeletal pain and restriction, weakness, spasticity, and cognitive impairment. Many variants of these same symptoms are routinely managed by physiatrists in patients without a history of cancer. Medical rehabilitation has been shown to be beneficial in both an outpatient setting and in an inpatient rehabilitation unit featuring a multidisciplinary team $[2,6]$. Physiatrists and multidisciplinary teams are also beneficial in helping cancer survivors return to work. An estimated $20 \%$ of cancer survivors have difficulty reintegrating into employment [7].

Helping a patient transition from active cancer treatment to treatment to restore physical and cognitive function can be difficult, but this transition is now an essential part of cancer care, and physiatrists are uniquely suited to address many survivorship needs. To underscore the need for medical rehabilitation of cancer survivors, the American Cancer Society has outlined and advocated for impairment-driven rehabilitation [8], which is a strategy based on identifying and addressing specific symptoms and areas of dysfunction, rather than more broadly recommending exercise and other less-focused approaches. For example, impairmentdriven rehabilitation would identify and treat radiation fibrosis as the underlying cause of shoulder pain in a breast cancer survivor, rather than simply prescribing an opioid analgesic or a generic form of physical therapy. Impairments can be classified as an acute or late effect, and properly identifying them as such may improve outcomes and provide a structure that can be used to monitor for predictable progression of symptoms. The American Cancer Society has specifically advocated that patients with particular, identifiable impairments be treated by a physiatrist and/or multidisciplinary team [8]. Although it is well documented that exercise and general physical activity reduce symptom burden and improve psychosocial well-being in persons with cancer [9], this approach fails to address specific problems that 
patients may already have or that develop subsequently as a late effect between initial oncology treatment and follow-up. Furthermore, nonspecific rehabilitation treatments may provide little structure to patients and often lack objective criteria by which to gauge response to treatment, thereby hindering the provider's ability to revise the plan of care. The rehabilitation of a specific impairment, such as pectoralis shortening and myofascial pain after a mastectomy and radiation therapy for breast cancer, requires a focused plan of action best developed by a physiatrist. A survivorship care plan provides an opportune time to begin the transition of care for musculoskeletal, neurologic, and cognitive symptom management to a physiatrist and ensure that there is no lapse in patient services.

\section{Challenges in Bringing Physiatric Care to Oncology Patients}

While new mandates provide an opportunity for the PM\&R specialty to expand its role in managing rehabilitation needs of oncology patients, many challenges remain. The program standards report of the Commission on Cancer places the onus of developing the survivorship care plan on oncologists [3], meaning that in order to reach patients with rehabilitation needs, physiatrists will have to act as consultants and rely on referrals. This approach is problematic for numerous reasons. For one, a 2014 study showed that only $52 \%$ of oncologists even provide a survivorship care plan despite the fact that this model, which will be mandatory in 2015, was first introduced in 2012 [10]. Second, Cheville et al [11] found that functional impairments are often underdiagnosed and underdocumented by oncology physicians, and referrals to specialists are lacking even when impairments are identified. Finally, even if an oncology provider identifies an impairment to be treated, the Commission on Cancer only advocates for "rehabilitation services," not PM\&R management specifically [3]. Theoretically, this lack of specificity can lead to improper referral of patients, such as to a physical therapist rather than to an occupational therapy edema specialist for lymphedema after an axillary lymph node dissection, or it can lead to patients being referred for only one impairment when physiatric management of multiple comorbidities is more appropriate.

Another potential obstacle arises when patients are referred to other physicians for management of functional impairment. Internal medicine and family medicine physicians will also play an integral role in survivorship care in the future, because they serve as primary care providers and see cancer survivors on a more frequent basis than do physiatrists as part of general care. Although cancer survivors benefit from preventative care services and cancer recurrence screenings by these providers, studies have shown that both oncology providers and primary care physicians do not believe that they have the proper training, nor the clinical time, to address physical and cognitive impairments that may be observed in this population $[12,13]$. This finding further emphasizes the importance of the PM\&R specialty's involvement, because these comorbidities are uniquely suited for physiatric management. It is unclear if the expectation of some oncology teams will be for primary care providers to manage or triage the management of these impairments, so physiatrists should make a concerted effort to establish their role as an essential component of survivorship care in this nascent stage of survivorship care plans.

Another barrier to better integrating physiatry with cancer survivorship care is the dearth of literature on the topic. Although some recent articles have espoused the benefits of rehabilitation in cancer care, more research is needed to better define the potential role of PM\&R in survivorship care, ideally with objective data to outline the benefits. In a PubMed search conducted at the time this article was written, articles about PM\&R and survivorship were sparse, often returning less than 10 articles in the search results. In the search queries that returned the most hits- "rehabilitation," "survivorship," and "rehabilitation' 'cancer survivorship," the results were often not about oncology, not about PM\&R, or neither. Some articles reported on the benefits of exercise in patients with cancer, which has been relatively well studied, but these articles do not address impairment-driven rehabilitation, which is a much more actionable and potentially effective model of providing patient care, as previously outlined. Although "cancer rehabilitation" has been discussed more than survivorship in the literature, it is broader and does not necessarily reflect the unique needs of long-term survivors in terms of management of late effects and preventing loss of function.

Historically, physiatric care of patients with cancer has been relatively limited. First outlined in 1971 by the National Cancer Act, cancer rehabilitation was conceptualized to improve the care of patients with cancer across the continuum of treatment, and this Act provided specific funding for projects to assess rehabilitation needs [14]. The National Cancer Act helped to establish many cancer rehabilitation programs throughout the 1970s and 1980s, although only about one third were headed by physiatrists [14]. Large cancer centers and academic institutions, such as Mayo Clinic, MD Anderson Cancer Center, and Memorial Sloan Kettering Cancer Center, were among the first programs to formally organize a rehabilitation department dedicated to patients with cancer. The number of programs is growing at a rapid clip, including relatively newer programs at the University of Michigan, the MedStar National Rehabilitation Hospital, the University of Miami, the University of Pennsylvania, and many more. This growth and programmatic enthusiasm represents a 
genuine opportunity to expand the scope of the PM\&R specialty.

Today, cancer rehabilitation represents a relatively small but growing subset of a field that has traditionally focused its research and clinical efforts on patients with spinal cord injury, amputation, traumatic brain injury, musculoskeletal dysfunction, and stroke (it is important to point out that rehabilitation of a patient with cancer often involves components of these diagnosis groups). Currently, at least 4 cancer rehabilitation fellowship training programs exist but are not accredited by the Accreditation Council for Graduate Medical Education. The scope of resident training in cancer rehabilitation is widely variable and largely dependent on faculty mentors at a given institution. The American Board of Physical Medicine \& Rehabilitation only requires approximately $1 \%-4 \%$ of the written board examination questions to ask about cancer-related issues [15], limiting the incentive for residency programs to increase educational emphasis. Despite this lack of focus in residency education, the first edition of the seminal textbook on the field, Cancer Rehabilitation: Principles and Practice, was edited by Michael Stubblefield, MD, and Michael O'Dell, MD, and published by Demos Medical in 2009.

\section{Strategies to Increase Involvement in Survivorship Care}

Although the PM\&R specialty has not traditionally focused as much on cancer rehabilitation compared with other subspecialties, survivorship care plans offer a unique opportunity to better integrate and formalize PM\&R's involvement along the continuum of cancer care. This goal may be accomplished in several ways. First, it is important for physiatrists to integrate into existing survivorship clinics and/or help develop new clinics. Survivorship clinics exist at many cancer centers and can be disease-specific or general. Typically, these clinics focus on surveillance and health maintenance. Although it is not known exactly how involved PM\&R is in each survivorship clinic, an Internet search of 15 prominent cancer centers' Web sites dedicated to adult survivorship clinics shows that descriptions of rehabilitation services are lacking (see Table 1 and Appendix 1). We found that rehabilitation services were mentioned in only $28 \%$ of these Web sites describing survivorship clinics. Additionally, in some of the instances in which PM\&R was mentioned, it was at only one of multiple survivorship clinics offered at the cancer center. Although this is by no means a conclusive analysis of PM\&R's involvement in various survivorship clinics, it may indicate a lack of communication to patients and oncology providers about the beneficial services that PM\&R can contribute within cancer care.

The benefits of physiatric care can be conveyed to oncology providers in several ways. For one, citing the
Table 1

Cancer center Web sites describing rehabilitation services in an adult survivorship clinic

\begin{tabular}{|c|c|c|}
\hline Cancer Center (Alphabetical) & $\begin{array}{l}\text { Survivorship Clinic } \\
\text { Web Sites }\end{array}$ & $\begin{array}{l}\text { Rehabilitation } \\
\text { Mentioned? }\end{array}$ \\
\hline $\begin{array}{l}\text { Samuel Oschin } \\
\text { Comprehensive Cancer } \\
\text { Institute (Cedars-Sinai) }\end{array}$ & G & $\mathrm{Yes}^{G}(1 / 1)$ \\
\hline City of Hope & $P, G$ & No $(0 / 2)$ \\
\hline Dana-Farber Cancer Institute & G & $\operatorname{Yes}^{\mathrm{G}}(1 / 1)$ \\
\hline $\begin{array}{l}\text { Winship Cancer Institute of } \\
\text { Emory University }\end{array}$ & G & No $(0 / 1)$ \\
\hline $\begin{array}{l}\text { Fred Hutchinson Cancer } \\
\text { Research Center }\end{array}$ & G & No $(0 / 1)$ \\
\hline $\begin{array}{l}\text { Sidney Kimmel } \\
\text { Comprehensive Cancer } \\
\text { Center (Johns-Hopkins) }\end{array}$ & G & $\operatorname{Yes}^{G}(1 / 1)$ \\
\hline Mayo Clinic Cancer Center & $B, O$ & $\mathrm{Yes}^{\mathrm{BO}}(3 / 4)$ \\
\hline MD Anderson Cancer Center & $\mathrm{B}, \mathrm{P}, \mathrm{O}$ & $\operatorname{Yes}^{\mathrm{O}}(1 / 11)$ \\
\hline $\begin{array}{l}\text { Memorial Sloan Kettering } \\
\text { Cancer Center }\end{array}$ & $B, P, S, O$ & Yes $^{\text {so }}(4 / 13)$ \\
\hline $\begin{array}{l}\text { Robert H Lurie Comprehensive } \\
\text { Cancer Center of } \\
\text { Northwestern University }\end{array}$ & $\mathrm{B}, \mathrm{G}, \mathrm{O}$ & Yes $^{B}(1 / 3)$ \\
\hline $\begin{array}{l}\text { UCLA's Jonsson } \\
\text { Comprehensive Cancer } \\
\text { Center }\end{array}$ & $\mathrm{B}, \mathrm{G}$ & No $(0 / 2)$ \\
\hline $\begin{array}{l}\text { University of Colorado Cancer } \\
\text { Center }\end{array}$ & G & No $(0 / 1)$ \\
\hline $\begin{array}{l}\text { University of Michigan } \\
\text { Comprehensive Cancer } \\
\text { Center }\end{array}$ & $B, P, S$ & Yes $^{\mathrm{S}}(1 / 3)$ \\
\hline $\begin{array}{l}\text { UNC Lineberger } \\
\text { Comprehensive Cancer } \\
\text { Center }\end{array}$ & G & No $(0 / 1)$ \\
\hline $\begin{array}{l}\text { Abramson Cancer Center of } \\
\text { the University of } \\
\text { Pennsylvania }\end{array}$ & G & No $(0 / 1)$ \\
\hline Total & & $28 \%(13 / 46)$ \\
\hline
\end{tabular}

$\mathrm{G}=$ general; $\mathrm{P}=$ prostate cancer; $\mathrm{B}=$ breast cancer; $\mathrm{O}=$ other; $\mathrm{S}=$ sarcoma.

See Appendix 1 for uniform resource locators accessed for this table.

American Cancer Society's advocacy of impairmentdriven cancer rehabilitation services [8] may lend credibility by way of pointing out that a prominent organization recognizes this patient care need. Additionally, attending oncology grand rounds and tumor boards can boost visibility and show that physiatrists take the care of this patient population seriously, thus creating familiarity between providers and generating referrals. As collaboration increases, working with oncology team members, including nurse practitioners and physician assistants, to establish referral algorithms will help ensure that patients with rehabilitative needs are properly referred. For example, a screening questionnaire for chemotherapy-induced cognitive dysfunction can be developed based on existing tools that measure cognitive deficits, and if a patient scores a given number, that patient is referred to a physiatrist. Physiatrists should conduct studies to create and validate such referral tools for patients with cancer. 
Finally, it is important to note that a dedicated cancer rehabilitation department at a cancer center is not necessary to provide oncology patients with access to medical rehabilitation; any physiatrist should be able to provide basic rehabilitation care, facilitate admission to an inpatient rehabilitation unit, and direct patients to important services about which an oncology clinician may not be familiar. Furthermore, any PM\&R physician should be versed in validated screening tools to objectively assess patients for disability and/or loss of function, even if the physiatrist is not familiar with common practices in oncology. Essentially, although a physiatrist who specializes in cancer rehabilitation may be able to provide a more sophisticated level of care to a cancer survivor, many patients would benefit from an evaluation by a physiatrist who has no cancer subspecialty training. If there is no cancer rehabilitation specialist in a practice or academic department, another physiatrist(s) can expand patient care services by reaching out to oncology teams.

\section{Conclusion}

Survivorship is a mandatory component of cancer care, and functional impairment as a result of the disease and/or its treatment may be optimally diagnosed and treated by a physiatrist. It appears that this aspect of patient care has been under-represented by physiatrists and that physiatrists are underutilized by oncology teams. As more patients with cancer become survivors and survivorship care plans become mandatory, formal care coordination between oncologists and physiatrists has the opportunity to provide improved patient outcomes and foster collaboration on research projects. Physiatrists should familiarize themselves with the Commission on Cancer mandates and actively work to become involved in survivorship care, and oncologists and allied health professionals should involve physiatrists when developing multidisciplinary survivorship plans and clinics. Residency program directors should increase curriculum emphasis on cancer rehabilitation to educate future physiatrists about an interesting and growing subspeciality within the field.

\section{References}

1. DeSantis CE, Lin CC, Marriotto AB, et al. Cancer treatment and survivorship statistics, 2014. CA Cancer J Clin 2014;64: 252-271.

2. Silver JK, Baima J, Mayer RS. Impairment-driven cancer rehabilitation: An essential component of quality care and survivorship. CA Cancer J Clin 2013;63:295-317.

3. American College of Surgeons Commission on Cancer. Cancer program standards 2012: Ensuring patient-centered care. Chicago, IL: American College of Surgeons; 2011.

4. Hewitt M, Greenfield S, Stovall E, eds. From Cancer Patient to Cancer Survivor: Lost in Transition. Washington, DC: National Academies Press; 2005.

5. American Society of Clinical Oncology. About cancer survivorship. Available at: http://www.cancer.net/survivorship/about-cancersurvivorship. Accessed January 5, 2015.

6. Stubblefield MD, Schmitz KH, Ness KK. Physical functioning and rehabilitation for the cancer survivor. Semin Oncol 2013;40: 784-795.

7. Short PF, Vargo MM. Responding to employment concerns of cancer survivors. J Clin Oncol 2006;24:5138-5141.

8. American Cancer Society. Cancer Treatment and Survivorship Facts \& Figures 2014-2015. Atlanta, GA: American Cancer Society; 2014.

9. Speck RM, Courneya KS, Masse LC, Duval S, Schmitz KS. An update of controlled physical activity trials in cancer survivors: A systematic review and meta-analysis. J Cancer Surviv 2010;4:87-100.

10. Salz T, McCabe MS, Onstad EE, et al. Survivorship care plans: Is there buy-in from community oncology providers? Cancer 2014; 120:722-730.

11. Cheville AL, Beck LA, Petersen TL, Marks RS, Gamble GL. The detection and treatment of cancer-related functional problems in an outpatient setting. Support Care Cancer 2009;17:61-67.

12. Virgo K, Lerro CC, Klabunde CN, Earle C, Ganz PA. Barriers to breast and colorectal cancer survivorship care: Perceptions of primary care physicians and medical oncologists in the United States. J Clin Oncol 2013;31:2322-2336.

13. Libert Y, Merckaert I, Slachmuylder JL, Razavi D. The ability of informal primary caregivers to accurately report cancer patients' difficulties. Psychooncology 2013;22:2840-2847.

14. Alfano CM, Ganz PA, Rowland JH, Hahn EE. Cancer survivorship and cancer rehabilitation: Revitalizing the link. J Clin Oncol 2012;30: 904-906.

15. American Board of Physical Medicine and Rehabilitation. Part I Certification Examination Outline. Available at: https://www. abpmr.org/partl/documents/PartlOutline_Weights.pdf. Accessed January 5, 2015.

\section{Disclosure}

S.R.S. University of Michigan, Department of Physical Medicine \& Rehabilitation, 325 E Eisenhower Pkwy, Ste 100, Ann Arbor, MI 48108. Address correspondence to: S.R.S.; e-mail: srsz@med.umich.edu

Disclosure: nothing to disclose

A.G.R. Good Shepherd Rehabilitation Hospital, Allentown, PA Disclosure: nothing to disclose
C.A. University of Michigan, Department of Physical Medicine \& Rehabilitation, 325 E Eisenhower Pkwy, Ste 100, Ann Arbor, Ml 48108 Disclosure: nothing to disclose

Submitted for publication November 11, 2014; accepted December 14, 2014. 
Appendix 1

Web sites of survivorship clinics that were evaluated for mention of rehabilitation*

- Samuel Oschin Comprehensive Cancer Institute (Cedars-Sinai): http://www.cedars-sinai.edu/Patients/Programs-and-Services/SamuelOschin-Comprehensive-Cancer-Institute-/Centers-and-Programs/Cancer-Survivorship-and-Rehabilitation/

- City of Hope: http://www.cityofhope.org/center-for-cancer-survivorship, http://www.cityofhope.org/center-for-cancer-survivorship\#ProstateCancerSurvivorshipProgram

- Dana-Farber Cancer Institute: http://www.dana-farber.org/Adult-Care/Treatment-and-Support/Treatment-Centers-and-Clinical-Services/ Adult-Survivorship-Program.aspx, http://www.dana-farber.org/For-Adult-Cancer-Survivors.aspx

- Winship Cancer Institute of Emory University: https://winshipcancer.emory.edu/patient-care/living-with-cancer/survivorship.html

- Fred Hutchinson Cancer Research Center: http://www.fredhutch.org/en/treatment/survivorship/survivorship-clinic.html

- Sidney Kimmel Comprehensive Cancer Center (Johns-Hopkins): http://www.hopkinsmedicine.org/kimmel_cancer_center/centers/ cancer_survivorship/our_experts

- Mayo Clinic Cancer Center: http://www.mayoclinic.org/departments-centers/oncology/cancer-survivorship-clinics/services, http://www.mayoclinic.org/departments-centers/oncology/cancer-survivorship-clinics/overview

- MD Anderson Cancer Center: http://www.mdanderson.org/patient-and-cancer-information/cancer-information/cancer-topics/ survivorship/follow-up-care/index.html

- Memorial Sloan Kettering Cancer Center: http://www.mskcc.org/pediatrics/adult-survivorship-team, http://www.mskcc.org/ cancer-care/survivorship/adult-survivorship, http://www.mskcc.org/pediatrics/adult-survivors-childhood, http://www.mskcc.org/ cancer-care/adult/soft-tissue-sarcoma/survivorship

- Robert H Lurie Comprehensive Cancer Center of Northwestern University: http://cancer.northwestern.edu/public/why_northwestern/ specialty_programs/programs/womens.cfm, http://cancer.northwestern.edu/public/why_northwestern/specialty_programs/programs/star. cfm, http://cancer.northwestern.edu/public/why_northwestern/specialty_programs/programs/soar.cfm

- UCLA's Jonsson Comprehensive Cancer Center: http://www.cancer.ucla.edu/Index.aspx?page=1250, http: / / www.cancer.ucla.edu/Index.aspx?page=590

- University of Colorado Cancer Center: http://www.ucdenver.edu/academics/colleges/medicalschool/centers/cancercenter/ CancerCare/survivors/Pages/survivors.aspx, https://www.uchealth.org/Pages/Services/Cancer-Care/Support-and-Education/SurvivorshipClinics.aspx

- University of Michigan Comprehensive Cancer Center: http://www.mcancer.org/support/survivorship, http://www.mcancer.org/ breast-cancer/survivorship, http://www.mcancer.org/prostate-cancer/survivorship, http://www.mcancer.org/sarcoma-survivorship/ sarcoma-survivorship-clinic

- UNC Lineberger Comprehensive Cancer Center: http://unclineberger.org/patientcare/programs/ccsp/programs/survivorship

- Abramson Cancer Center of the University of Pennsylvania: http://www.penncancer.org/patients/centers-programs-services/ livestrong-cancer-survivorship-center/

\footnotetext{
* Some links list diagnosis-specific clinics. Accessed January 5, 2015.
} 